\title{
Efektivitas Model Pembelajaran Jigsaw pada Keterampilan Menulis Bahasa Perancis
}

\author{
Tri Indri Hardini, Iim Siti Karimah, \& Adelya Erliani \\ Departemen Pendidikan Bahasa Perancis \\ Universitas Pendidikan Indonesia \\ tihardini@upi.edu; iimsitikarimah@upi.edu; adelyaerliani23@gmail.com
}

How to cite (in APA Style): Hardini, T.I., Karimah, I.S., \& Erliani, A. (2020). Efektivitas model pembelajaran jigsaw pada keterampilan menulis bahasa Perancis. Jurnal Pendidikan Babasa dan Sastra, 20(1), 121-131. DOI: https://doi.org/10.17509/bs_jpbsp.v20i1.25977

Article History: Received (15 December 2019); Revised (15 February 2020); Accepted (1 April 2020)

Journal homepage: http://ejournal.upi.edu./index.php/BS_JPBSP

\begin{abstract}
Abstrak: Penelitian ini bertujuan untuk mendapatkan informasi perihal kemampuan menulis bahasa Perancis mahasiswa sebelum dan sesudah diterapkannya model Jigsaw, efektivitas model pembelajaran Jigsaw dalam keterampilan menulis, dan kelebihan dan kelemahan model Jigsaw dalam keterampilan menulis. Penelitian ini menggunakan metode deskriptif kuantitatif dalam bentuk praeksperimen. Instrumen yang digunakan berupa tes dan angket. Sampel penelitian ini adalah karakteristik keterampilan menulis bahasa Perancis mahasiswa semester VI Departemen Pendidikan Bahasa Perancis FPBS UPI. Subjek yang digunakan berjumlah 32 responden. Berdasarkan hasil penelitian, dapat disimpulkan bahwa responden telah mampu menulis teks argumentatif bahasa Perancis dengan baik. Hal ini dapat diketahui dari nilai rata-rata tes responden setelah mendapatkan perlakuan adalah sebesar 8,9, yang mengalami kenaikan ratarata nilai pascates dibandingkan dengan rata-rata nilai prates sebesar $1,7 \%$. Hasil penelitian menunjukkan bahwa pada umumnya mahasiswa menyukai menulis bahasa Perancis namun mereka menemukan banyak kesulitan dalam membuat tulisan dalam bahasa Perancis. Sebagian besar mahasiswa memberikan kesan positif terhadap model pembelajaran Jigsaw.
\end{abstract}

Kata kunci: keterampilan menulis; model pembelajaran jigsaw; teks argumentatif

\section{Effectiveness of Jigsaw Learning Models in French Writing Skills}

\begin{abstract}
This research aims to describe student's writing ability before and after using Jigsaw model, the effectiveness of Jigsaw model in improving writing skills, and the opinion of students. This study applies descriptive quantitative method in form of pre-experimental design. Instruments that are used in the form of tests and questionnaires. The sample of this research is 32 characteristics writing skill of $6^{\text {th }}$ semester French Education students. Based on the research result, the researcher can conclude that the students have been able to write the argumentative text nicely. The test result showed that the average test score after using the Jigsaw model is 8.9. It means, the average posttest score is higher than the average pretest score, up to $1.7 \%$. Meanwhile, the results of the questionnaire show that students like writing but they find so much difficulty in making a writing or a text, and most students give a positive impression for the Jigsaw model.
\end{abstract}

Keywords: writing skill; jigsaw model; the argumentative text 


\section{PENDAHULUAN}

Saat ini, bahasa Perancis merupakan salah satu bahasa yang banyak digunakan oleh masyarakat di dunia, tak terkecuali di Indonesia. Tidak hanya keterampilan berbicara, untuk menguasai bahasa, kita dituntut untuk menguasai keterampilan lainnya, yaitu keterampilan menyimak, membaca, dan menulis. Setiap keterampilan berbahasa mempunyai tingkat kesulitan yang berbeda.

Berbagai model dan media pembelajaran dikembangkan dengan cara yang beragam agar pembelajar dapat menangkap dengan mudah pembelajaran bahasa yang dimaksud. Keterampilan menulis dianggap sebagai keterampilan berbahasa yang cukup sulit untuk dipelajari. Keterampilan menulis merupakan keterampilan yang memiliki tingkat kesulitan yang tinggi bagi pembelajar dibanding dengan tiga keterampilan berbahasa lainnya". (Iskandarwassid \& Sunendar, 2008; Sunendar, Cahyani, \& Mulyadi, 2014).

Dalam pembelajaran keterampilan menulis bahasa Perancis, khususnya dalam tingkat DELF B1, pembelajar harus menguasai penulisan yang terstruktur dan penulisan teks yang cukup panjang dengan memperhatikan tata bahasa, struktur kalimat, konten teks, dan lainnya. Salah satu teks yang dipelajari dalam tingkat B1 adalah teks argumentatif. Teks argumentatif adalah teks yang berisi argumen dan sudut pandang dengan tujuan untuk meyakinkan pembaca.

$$
\text { Pada laman Le Monde (n.d) }
$$

diungkapkan bahwa, "tout texte argumentatif défend une prise de position en s'opposant implicitement ou explicitement à ceux qui pensent le contraire. Si le texte n'est pas adressé à l'adversaire lui-même, il vise à empêcher le lecteur de prendre cet adversaire an sérienx. Si le texte est directement adressé à l'adversaire, il vise à reduire l'autre au silence, sans chercher à le convaincre" [teks argumentatif mengedepankan penempatan sudut pandang dengan menghindari secara tersirat atau tidak kepada pembaca yang berpikir hal yang bertentangan. Jika bacaan tersebut tidak ditujukan kepada pembaca yang tidak setuju, maka bacaan tersebut dimaksudkan untuk mencegah pembaca lain untuk setuju akan pendapat lain. Jika bacaan secara langsung ditujukan kepada pembaca yang tidak setuju, maka teks tersebut dimaksudkan untuk mengurangi pembaca lain untuk tidak berpendapat, tanpa mencari hal untuk meyakinkan pembaca lain]. Dalam membuat teks argumentatif, pembelajar dituntut untuk mempunyai banyak kosa kata, gagasan yang bagus dan kalimat yang bagus pula. Jadi, pengajar harus mengajarkan secara jelas tahap-tahap untuk merangkai teks argumentatif dengan baik dan mudah.

Tentunya penjelasan dari pengajar saja bukan menjadi satu-satunya cara untuk membuat pembelajar mengerti dan menjadikan pembelajar mudah dalam membuat teks argumentatif. Pembelajar dan pengajar membutuhkan metode atau model pembelajaran agar pembelajaran menjadi lebih mudah. Sudah banyak model pembelajaran yang diterapkan dalam pembelajaran bahasa. Salah satunya adalah model pembelajaran Jigsaw. Model Jigsaw telah dikembangkan pada tahun 1978 oleh Elliot Aronson. Mijon (2010) mengungkapkan bahwa, Jigsaw-Teaching prévoit dans un premier temps un travail a réaliser individuellement; elle réunit dans un deuxième temps des sousgroupes «d'experts》 (c'est-à-dire ceux ayant travaillé individuellement sur la même tâche) qui échangent leurs connaissances afin de les développer; dans un troisième temps, elle redistribue les apprenants en sous-groupes constitués cette fois de représentants de chaque groupe «d'experts»: ceux-ci partagent alors leurs connaissances pour réaliser une nouvelle tâche.

[Pertama-tama dalam pengajaran Jigsaw, diharuskan untuk bekerja secara individual terlebih dahulu; langkah kedua yaitu membagi kepada sub kelompok "ahli" (yaitu orangorang yang telah bekerja pada topik yang sama secara individu) yang selanjutnya berbagi pengetahuan untuk dikembangkan; ketiga, 
mendistribusikan kembali peserta didik menjadi sub kelompok yang kali ini adalah perwakilan dari setiap kelompok "ahli": mereka kemudian berbagi pengetahuan untuk melakukan tugas baru].

Dengan demikian, dapat diartikan bahwa model pembelajaran Jigsaw adalah sebuah model pembelajaran dari metode kooperatif di mana pembelajar mempelajari materi pembelajaran dalam sebuah kelompok. Dalam hal ini, pembelajar mempelajari materi dalam sebuah kelompok untuk berdiskusi namun mereka juga bekerja secara individu. Bahkan, pembelajar dapat berbagi gagasan dengan teman sekelompok dalam "kelompok ahli" jadi, pembelajar dapat terbantu dalam memperkaya isi atau konten teks.

Beberapa penelitian yang membahas tentang metode jigsaw dilakukan di antaranya oleh Kurbani (2015) dan Syahrin (2015) yang menunjukkan bahwa metode ini efektif untuk pembelajaran.

Berdasarkan teori-teori yang telah dipaparkan sebelumnya, peneliti akan memaparkan langkah-langkah tentang penggunaan metode tersebut di antaranya sebagai berikut:

1. Membagi setiap pembelajar ke dalam delapan (8) kelompok yang terdiri dari empat (4) orang pembelajar secara heterogen.

2. Setiap anggota dari sebuah kelompok akan mendapatkan sebuah topik dari materi yang berbeda-beda, begitupun dengan kelompok yang lain.

3. Setiap pembelajar harus mempelajari topik yang diberi dengan seksama terlebih dahulu dan merancang kerangka teks argumentatif sekitar 15 menit.

4. Setelah membuat kerangka teks, para pembelajar akan dikumpulkan dalam kelompok tim ahli dimana dalam kelompok tim ahli adalah para pembelajar yang mempunyai topik yang sama tetapi berbeda kelompok asal.

5. Dalam kelompok tim ahli ini, pembelajar berdiskusi tentang topik dan teks argumentatif yang dibuat dengan tujuan agar dapat menambah informasi dan memperluas ide untuk melengkapi teks yang dibuat oleh masing-masing anggota.

6. Setelah diskusi dalam kelompok tim ahli dinilai cukup, setiap anggota pembelajar kembali ke kelompok asal dan menyelesaikan tugas secara individual terlebih dahulu.

7. Kemudian, para pembelajar dapat tampil dalam kelompoknya masingmasing untuk menyimpulkan apa yang dibuat dan didapatkan dalam kelompok tim ahli.

Teks argumentatif dalam bahasa Perancis dalam penerapannya termasuk pada tingkat B1 menurut CECRL. Dalam penelitian ini, keterampilan menulis teks argumentatif di sini diharapkan sesuai dengan standar tes keterampilan menulis (production écrite) tingkat B1. Menurut CECRL, standar tes keterampilan menulis dalam DELF tingkat B1 adalah: :'Je peux écrive un texte simple et cohérent sur des sujet familiers ou qui m'interessent personnellement. Je peux écrire des lettres personnelles pour décrire expérience et impressions," [saya dapat menulis sebuah teks sederhana dan koheren tentang subjek yang umum yang saya senangi secara pribadi. Saya dapat menulis surat pribadi yang menceritakan pengalaman dan kesan.]

Untuk mencapai standar yang telah ditentukan, banyak aspek yang dinilai dalam tes keterampilan menulis bahasa Perancis (production écrite). Berikut merupakan tabel penilaian tes keterampilan menulis bahasa Perancis (DELF) tingkat B1: 
Tabel 1. Format Penilaian Tes Keterampilan Menulis (Production écrite) dalam DELF Tingkat B1

\begin{tabular}{|c|c|c|c|c|c|c|c|c|c|}
\hline $\begin{array}{l}\text { Respect de la consigne } \\
\text { Peut mettre en adéquation sa production avec le sujet proposé. } \\
\text { Respecte la consigne de longueur minimale indiquée. }\end{array}$ & 0 & 0,5 & 1 & 1,5 & 2 & & & & \\
\hline $\begin{array}{l}\text { Capacité à présenter des faits } \\
\text { Peut décrire des faits, des événement ou des expériences. }\end{array}$ & 0 & 0,5 & 1 & 1,5 & 2 & 2,5 & 3 & 3,5 & 4 \\
\hline $\begin{array}{l}\text { Capacité à exprimer sa pensée } \\
\text { Peut présenter ses idées, ses sentiments et ou ses réactions et donner son opinio }\end{array}$ & 0 & 0,5 & 1 & 1,5 & 2 & 2,5 & 3 & 3,5 & 4 \\
\hline $\begin{array}{l}\text { Cohérence et cohésion } \\
\text { Peut relier une série d'éléments courts, simples et distincts en un discours qui } \\
\text { s'enchaîne. }\end{array}$ & 0 & 0,5 & 1 & 1,5 & 2 & 2,5 & 3 & & \\
\hline \multicolumn{10}{|l|}{ Compétence lexicale / orthographe lexicale } \\
\hline $\begin{array}{l}\text { Étendue du vocabulaire } \\
\text { Possède un vocabulaire suffisant pour s'exprimer sur des sujets courants, si } \\
\text { nécessaire à l'aide de périphrase. }\end{array}$ & 0 & 0,5 & 1 & 1,5 & 2 & & & & \\
\hline $\begin{array}{l}\text { Maîtrise du vocabulaire } \\
\text { Montre une bonne maittrise du vocabulaire élémentaire mais des erreurs sérieuse } \\
\text { produisent encore quand il s'agit d'exprimer une pensée plus complexe. }\end{array}$ & 0 & 0,5 & 1 & 1,5 & 2 & & & & \\
\hline $\begin{array}{l}\text { Maîtrise de l'orthographe lexicale } \\
\text { L'orthographe lexicale, la punctuation et la mise en page sont assez justes pour } \\
\text { suivies facilement le plus souvent }\end{array}$ & 0 & 0,5 & 1 & 1,5 & 2 & & & & \\
\hline \multicolumn{6}{|l|}{ Compétence grammaticale / orthographe grammaticale } & & & & \\
\hline $\begin{array}{l}\text { Degré d'élaboration des phrases } \\
\text { Maitrise bien la structure de la phrase simple et les phrases complexes les plus } \\
\text { courantes }\end{array}$ & 0 & 0,5 & 1 & 1,5 & 2 & & & & \\
\hline $\begin{array}{l}\text { Choix des temps et des modes } \\
\text { Fait prevue d'un bon contrôle malgré de nettes influences de la langue maternell }\end{array}$ & 0 & 0,5 & 1 & 1,5 & 2 & & & & \\
\hline $\begin{array}{l}\text { Morphosyntaxe - orthographe grammaticale } \\
\text { Accord en genre et en nombre, pronoms, marques verbales, etc. }\end{array}$ & 0 & 0,5 & 1 & 1,5 & 2 & & & & \\
\hline
\end{tabular}

(Conseil de l'Europe, 2005)

Tabel di atas merupakan format penilaian tes keterampilan menulis (production écrite) menurut standar DELF tingkat B1. Penilaian dalam tes yang dilaksanakan dalam penelitian ini sedikit mengacu kepada format penilaian tes keterampilan menulis (production écrite) standar DELF tingkat B1, namun penilaian di sini dibuat lebih sederhana. Teks argumentatif yang dibuat oleh peserta didik diharapkan dapat sesuai dengan standar DELF tingkat B1 dengan topik serta tata bahasa yang sesuai.

Pembelajar harus menguasai cara merangkai sebuat teks yang didalamnya terdapat argumen atau opini. Dalam hal ini, pembelajar tidak hanya mengungkapkan gagasan dan opini namun juga harus meyakinkan pembaca akan gagasan dan opini tersebut. Menurut Keraf (2004), teks argumentatif merupakan sebuah retorika yang berupaya untuk mempengaruhi perilaku atau opini pembaca agar mereka percaya dan setuju dengan penulis pada akhirnya.
Bukan hal yang mudah untuk membuat sebuah teks argumentatif yang berisi opini serta gagasan juga untuk mempengaruhi para pembaca. Dengan standar tingkat B1 dalam CECRL, semakin membuat sulit untuk membuat sebuah teks bagi para pembelajar, karena pembelajar harus memperhatikan segi tata bahasa, kosa kata, dan juga keseluruhan konten teks yang harus mudah dipahami oleh pembaca. Berdasarkan kesulitan tersebut, pengajar berkewajiban menyampaikan dengan jelas dan harus menggali lebih dalam tentang model-model pembelajaran yang dapat mengurangi kesulitan tersebut. Adapun tujuan dari penelitian ini adalah untuk memperoleh data: 1) kemampuan menulis teks bahasa Perancis mahasiswa sebelum dan sesudah diterapkannya model Jigsaw; 2) efektivitas model Jigsaw dalam keterampilan menulis bahasa Perancis, dan 3) kelebihan serta kekurangan penerapan model Jigsaw dalam keterampilan menulis bahasa Perancis. 


\section{METODE}

Dalam penelitian ini, peneliti menggunakan metode deskriptif kuantitatif dengan desain pra eksperimental dengan konsep kelompok prates dan pascates. Sampel dari penelitian ini adalah karakteristik keterampilan menulis dalam bahasa Perancis, khususnya jenis teks argumentatif, mahasiswa semester VI kelas A pada Departemen Pendidikan Bahasa Perancis FPBS UPI. Penelitian ini memiliki dua variabel, yaitu variabel bebas (independen) dan variabel terikat (dependen). Variabel bebas dari penelitian ini adalah ketermpilan menulis teks argumentatif dalam bahasa Perancis dan variabel terikat dalam penelitian ini adalah model pembelajaran Jigsaw. Dalam penelitian ini, peneliti menggunakan dua teknik pengumpulan data yaitu: tes (prates dan pascates) dan angket tentang kegiatan menulis dan penggunaan model pembelajaran Jigsaw dalam pembelajaran keterampilan menulis teks argumentatif dalam bahasa Perancis.

\section{HASIL DAN PEMBAHASAN}

Terdapat tiga langkah dalam penelitian ini yaitu: prates, perlakuan dan pascates. Pada tahap prates mahasiswa diminta untuk mengerjakan tes membuat teks argumentatif sesuai dengan topik yaitu: "Qu'est-ce que vous pensez de la télévision? La télévision, ses avantages et ses incovénients" dan sesuai dengan standar CECRL DELF B1 yaitu teks dengan jumlah kata $160-180$ kata. Alokasi waktu pengerjaan tes yaitu selama 45 menit.

Pada tahap perlakuan peneliti menerapkan model pembelajaran Jigsaw dalam keterampilan menulis teks argumentatif dengan tingkat B1 CECRL dengan 160-180 kata selama 90 menit. Model Jigsaw telah dikembangkan dan diuji coba oleh Elliot Aronson dkk di Universitas Texas, lalu Slavin dkk mengadaptasi model tersebut di Universitas Jhon Hopkins. Ditinjau dari sisi etimologi, kata jigsaw berasal dari bahasa Inggris yang berarti "gergaji ukir". Ada juga yang menyebutnya dengan istilah puzzle, yang mengidentikan dengan sebuah teka teki yang menyusun potongan gambar. Model Jigsaw ini mengambil pola cara bekerja sebuah gergaji sesuai dengan pengertian jigsaw sendiri, yang berarti siswa melakukan kegiatan belajar dengan cara bekerja sama dengan siswa lain untuk mencapai tujuan bersama.

Lie dalam Majid (2013, p.182) mengungkapkan bahwa pembelajaran kooperatif model jigsaw ini merupakan model belajar kooperatif dengan cara siswa belajar dalam kelompok kecil yang terdiri atas empat sampai dengan enam orang secara heterogen, dan siswa bekerja sama saling ketergantungan positif dan bertanggung jawab secara mandiri. Selain itu, Yuwono (2014, p.5) mengungkapkan bahwa, "pembelajaran jigsaw merupakan pembelajaran melalui penggunaan kelompok kecil siswa yang bekerja sama dalam memaksimalkan kondisi belajar yang maksimal untuk mencari tujuan pembelajaran dan mendapatkan pengalaman belajar yang maksimal, baik pengalaman individu ataupun pengalaman kelompok". Lalu, Anggraeni dan Yonanda (2018) juga menyatakan bahwa metode jigsaw memiliki tiga karakteristik, yaitu: kelompok kecil, belajar bersama, dan pengalaman belajar.

Dalam terapan tipe jigsaw, setelah siswa dibagi dalam kelompok belajar heterogen, setiap anggota dalam kelompok memiliki tanggung jawab untuk menyelesaikan tugas tertentu dari bahan yang dibagikan. Anggota dari kelompok yang lain mendapat tugas topik yang sama, yakni berkumpul dan berdiskusi tentang topik tersebut. Kelompok ini disebut dengan kelompok ahli (Ibrahim, et al., dalam Majid, 2013,p.182). Hal yang sama diungkapkan oleh Artut dan Tarim (2007, p.130) bahwa, "In this case, students were assigned to a six-member team where each individual worked on a different section of academic material. This was repeated across a number of teams. Following this each member of the different teams who studied the same sections met in $<<$ expert groups $>>$ and returned to their original teams and took turns teaching their teammates about their area of expertise" [dalam hal ini, peserta didik dibagi kedalam kelompok 
beranggotakan enam orang dimana setiap anggota bekerja secara individu dengan materi pembelajaran yang berbeda. Hal ini berlaku pula bagi kelompok yang lain. Selanjutnya, setiap anggota dari kelompok yang berbeda tetapi mempelajari materi yang sama akan bertemu di kelompok yang dinamakan "tim ahli" dan kembali kepada kelompoknya masing-masing kemudian bertugas untuk menjelaskan tentang materi yang didiskusikan di "tim ahli"]. Pendapat yang sama diungkapkan oleh Mijon (2010) bahwa,

"Tigsaw-Teaching prévoit dans un premier temps un travail a réaliser individuellement; elle réunit dans un deuxième temps des sousgroupes «d'experts》 (c'est-à-dire ceux ayant travaillé individuellement sur la même tâche) qui échangent leurs connaissances afin de les développer; dans un troisième temps, elle redistribue les apprenants en sous-groupes constitués cette fois de représentants de chaque groupe «d'experts»: ceux ci partagent alors leurs connaissances pour réaliser une nouvelle tâche"

Pertama-tama dalam pengajaran Jigsaw, diharuskan untuk bekerja secara individual terlebih dahulu; langkah kedua yaitu membagi kepada sub kelompok "ahli" (yaitu orangorang yang telah bekerja pada topik yang sama secara individu) yang selanjutnya berbagi pengetahuan untuk dikembangkan; ketiga, mendistribusikan kembali peserta didik menjadi sub kelompok yang kali ini adalah perwakilan dari setiap kelompok "ahli": mereka kemudian berbagi pengetahuan untuk melakukan tugas baru].

Langkah-langkah model jigsaw dibagi menjadi enam tahapan menurut Nurhadi dan Gerrard (2003) dalam Majid (2013, p.182-183), yaitu:

a. Menyampaikan tujuan belajar dan membangkitkan motivasi;

b. Menyajikan informasi kepada siswa dengan demonstrasi disertai penjelasan verbal, buku teks, atau bentuk lain; c. Mengorganisasikan siswa ke dalam kelompok belajar;

d. Mengelola dan membantu siswa dalam belajar kelompok dan kerja di tempat duduk masing-masing;

e. Mengetes penguasaan kelompok atas bahan ajar;

f. Pemberian penghargaan atau pengakuan terhadap hasil belajar siswa".

Adapun menurut Warsono dan Hariyanto (2012, p.196), sintaks atau cara kerja model jigsaw di antaranya:

a. Seluruh siswa dalam kelas dibagi menjadi kelompok-kelompok beranggotakan sekitar lima orang atau empat orang (Spencer Kagan dalam hal ini mengikut saja dan tidak berpendapat sendiri sehingga ia juga menyarankan 5 orang, sedangkan Laura Candler berdasarkan hasil penelitiannya, serta banyak ahli yang lain menyukai terdiri dari 4 orang saja);

b. Tunjuk salah seorang siswa dari setiap kelompok sebagai pemimpin;

c. Bagi-bagilah materi pembelajaran menjadi sejumlah segmen sesuai dengan jumlah siswa dalam kelompok;

d. Tugasilah setiap siswa dalam setiap kelompok untuk mempelajari hanya satu bagian/segmen saja dari materi pelajaran tersebut. Jadi jika ada empat orang di setiap kelompok, maka ada 4 orang siswa yang masing-masing mempelajari bagianbagian yang berbeda;

e. Kemudian setiap siswa dalam kelompok dikumpulkan dalam kelompok tim ahli. Setiap kelompok tim ahli beranggotakan siswa dari berbagai kelompok dengan tugas mempelajari segmen yang sama. Sebaiknya siswa yang dikirim dalam kelompok tim ahli adalah rekan mereka yang kompeten dan cepat belajar;

f. Para kelompok tim ahli (expert) tersebut kemudian berdiskusi membahas masalah yang sama; 
g. Kelompok tim ahli kemudian pulang kembali ke kelompok asalnya masing-masing;

h. Setiap anggota tim ahli menjelaskan hasil diskusi dalam kelompok tim ahli yang didatanginya atas nama kelompok tadi kepada para anggota kelompoknya yang lain.

Dalam pelaksanaannya, pembelajaran kooperatif model jigsaw memiliki kelebihan dan kekurangan menurut Ibrahim, et al., dalam Majid (2013,p.184), di antara kelebihannya adalah: a) dapat memberikan kesempatan kepada siswa untuk bekerjasama dengan siswa lain; b) Siswa dapat menguasai pelajaran yang disampaikan; c) Setiap anggota siswa berhak menjadi ahli dalam kelompoknya; d) dalam proses belajar mengajar siswa saling ketergantungan positif; e) setiap siswa dapat saling mengisi satu sama lain. Sedangkan kekurangannya adalah: a) siswa yang pandai cenderung tidak mau disatukan dengan temannya yang kurang pandai, dan yang kurang pandai pun merasa minder apabila digabungkan dengan temannya yang pandai, walaupun lama kelamaan perasaan itu akan hilang dengan sendirinya.

Dapat disimpulkan bahwa pembelajaran kooperatif model jugsaw ini mengandalkan kerja dalam kelompok namun setiap anggota tetap mempunyai tanggung jawab masing-masing karena dibebankan untuk mempelajari bagian dari materi yang berbeda-beda dari anggota kelompoknya. Selanjutnya anggota kelompok dapat mendiskusikan materi yang menjadi tugasnya di dalam kelompok ahli (expert) untuk mendapatkan beberapa tambahan ide atau sumber untuk materi yang dibahas.

Pertama-tama, peneliti menjelaskan terlebih dahulu tentang teks argumentatif secara singkat. Model pembelajaran Jigsaw kembali dijelaskan untuk mengingatkan pembelajar tentang ketentuan teks argumentatif. Lalu, penerapan model pembelajaran Jigsaw. Kami membagi pembelajar dalam 8 kelompok beranggotakan 4 orang. Setiap anggota kelompok akan mendapatkan sebuah topik yang berbeda-beda. Lalu, pembelajar terlebih dahulu mempelajari topik tersebut dan membuat kerangka karangan selama 15 menit. Setelah itu, pembelajar diminta untuk bergabung dengan "kelompok ahli" dimana pembelajar akan mendiskusikan topik yang sama selama 30 menit. Setelah diskusi selesai, pembelajar kembali ke kelompok asal untuk menyelesaikan teks yang dibuat. Setelah menyelesaikan teks, pembelajar harus mempresentasikan tentang teks yang mereka buat kepada anggota kelompok lain sehingga seluruh anggota kelompok dapat mengetahui tentang topik yang dipelajari oleh pembelajar. Terakhir, peneliti meminta perwakilan dari masing-masing kelompok untuk memberikan kesimpulan masingmasing topik di dalam kelompoknya secara singkat dan membuat kesimpulan secara bersama-sama. langkah-langkah tentang penggunaan metode tersebut di antaranya sebagai berikut:

1. Membagi setiap pembelajar ke dalam lima (5) kelompok yang terdiri dari empat (4) orang pembelajar secara heterogen.

2. Setiap anggota dari sebuah kelompok akan mendapatkan sebuah topik dari materi yang berbeda-beda, begitupun dengan kelompok yang lain.

3. Setiap pembelajar akan membuat sebuah teks argumentatif secara bersama-sama yang berdasar kepada topik yang sudah diberikan kepada setiap anggota kelompok.

4. Ketika pembelajar sedang membuat teks argumentatif, para pembelajar akan dikumpulkan dalam kelompok tim ahli dimana dalam kelompok tim ahli adalah para pembelajar yang mempunyai topik yang sama tetapi berbeda kelompok asal.

5. Dalam kelompok tim ahli ini, pembelajar berdiskusi tentang topik dan teks argumentatif yang dibuat dengan tujuan agar dapat menambah informasi dan memperluas ide untuk melengkapi 
teks yang dibuat oleh masingmasing anggota.

6. Setelah diskusi dalam kelompok tim ahli dinilai cukup, setiap anggota pembelajar kembali ke kelompok asal dan menyelesaikan tugas secara individual terlebih dahulu.

7. Kemudian, para pembelajar dapat tampil dalam kelompoknya masing- masing untuk menyimpulkan apa yang dibuat dan didapatkan dalam kelompok tim ahli.

Berikut rangkuman proses model pembelajaran Jigsaw pada pembelajaran menulis teks argumentatif dalam bahasa Perancis dalam bentuk bagan.

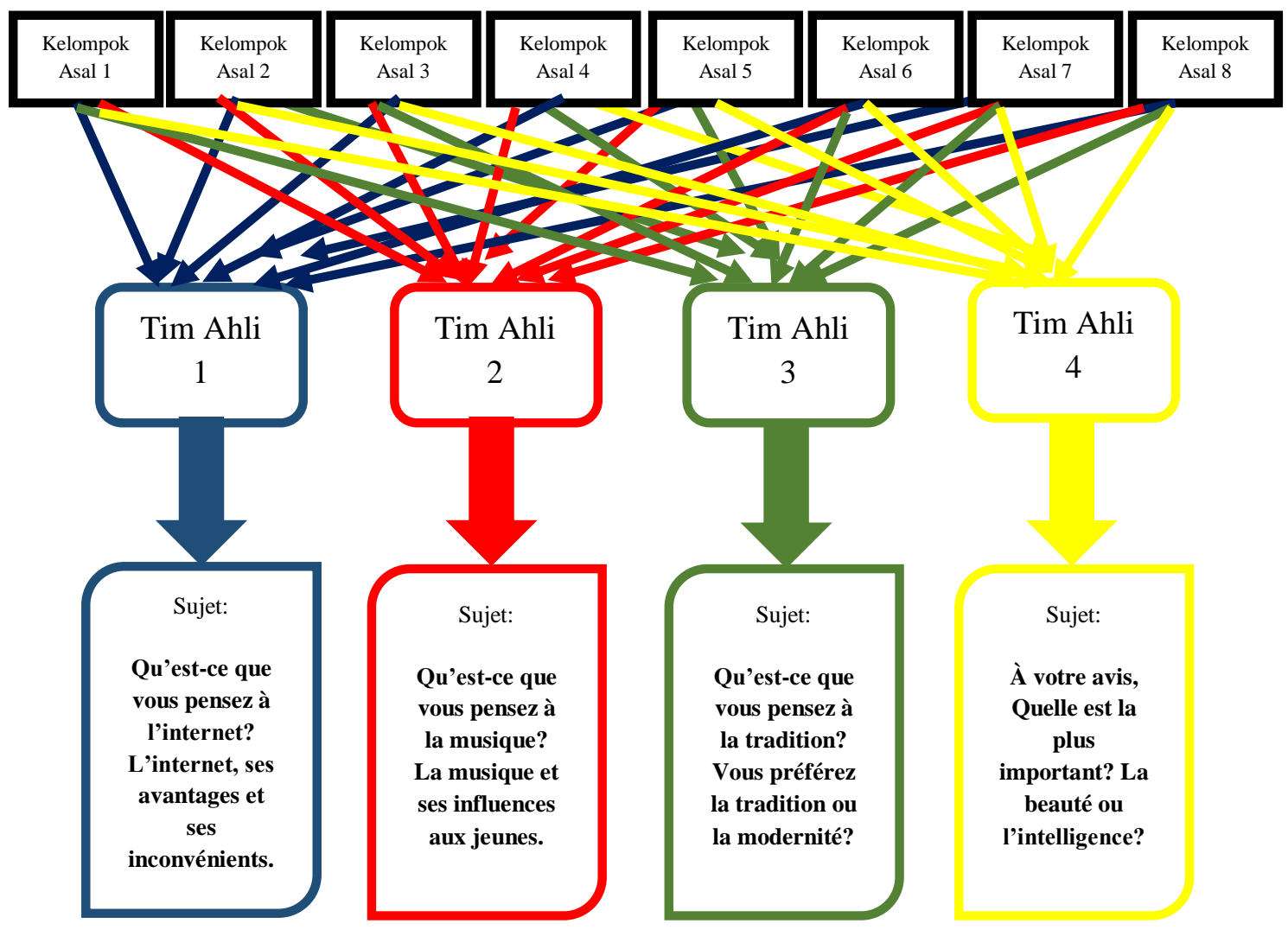

Gambar 1. Proses Model Pembelajaran Jigsaw

Pada tahap evaluasi, peneliti meminta perwakilan dari masing-masing kelompok untuk memberikan kesimpulan masingmasing topik di dalam kelompoknya secara singkat dan membuat kesimpulan secara bersama-sama. Tahap evaluasi ini berlangsung selama 15 menit. Selama proses pembelajaran, peneliti didampingi oleh pengamat yang bertugas mengisi lembar observasi peneliti dan responden yang telah disediakan oleh peneliti sebagai data pendukung dalam penelitian ini. Dari hasil pengamatan, peneliti dan pengamat menilai bahwa proses pembelajaran berjalan cukup baik dan efisien. Hal ini dapat dibuktikan dengan antusiasme responden dalam mengikuti proses pembelajaran, responden berdiskusi dan berbagi ide serta gagasan, baik dengan kelompok "tim ahli" maupun kelompok awal. Setelah semuanya selesai, peneliti kembali memberi motivasi kepada responden agar responden dapat melaksanakan tahap terakhir yaitu pascates.

Pada tahap pascates mahasiswa diminta untuk mengerjakan tes membuat teks argumentatif dengan satu topik yang 
sama, yaitu "Qu'est-ce que vous pensez de la cigarette? Est-ce que c'est bien ou non?". Sama halnya dengan prates, mahasiswa hanya perlu membuat teks argumentatif sesuai dengan topik yang telah ditentukan dan sesuai dengan standar CECRL DELF B1 yaitu teks dengan jumlah kata $160-180$ kata. Alokasi waktu pengerjaan tes yaitu selama 45 menit. Lalu berlanjut dengan pengisian angket dengan 15 pertanyaan tertutup tentang kegiatan menulis bahasa Perancis dan penggunaan model pembelajaran Jigsaw dalam pembelajaran keterampilan menulis teks argumentatif dalam bahasa Perancis.
Peneliti menggolongkan nilai ke dalam tiga kategori, yaitu: Skor Tinggi (11-15), Skor Menengah (6-10.5), dan Skor Rendah (15.5)

- Hasil dari prates menunjukkan bahwa terdapat 3 mahasiswa termasuk kategori Skor Tinggi, 17 orang termasuk kategori Skor Menengah dan 12 orang termasuk kategori Skor Rendah.

- Lalu hasil pascates menunjukkan terdapat 3 orang termasuk kategori Skor Tinggi, 27 orang termasuk kategori Skor Menengah dan 2 orang termasuk kategori Skor Rendah.

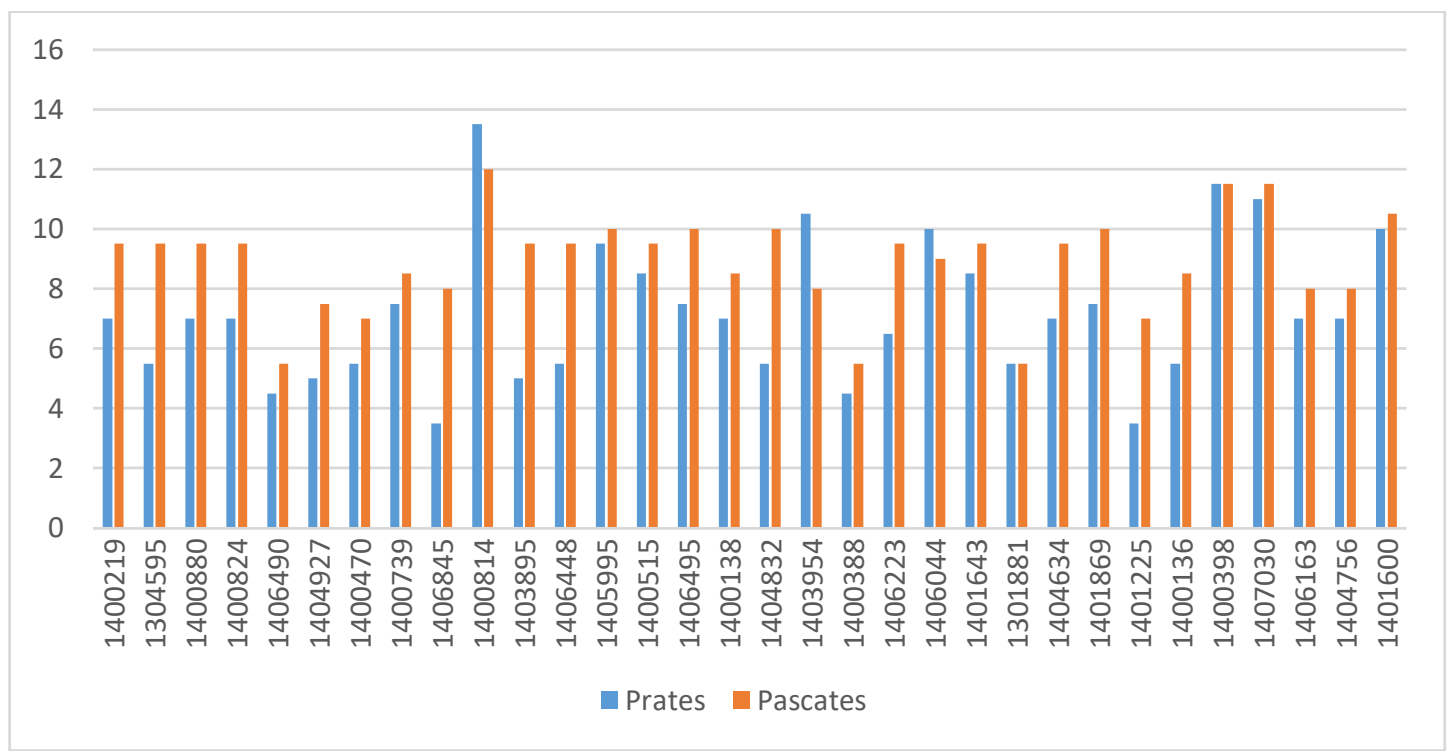

Grafik 1. Perbandingan antara nilai prates dan pascates.

Grafik di atas menunjukkan bahwa terdapat 27 mahasiswa yang mendapatkan nilai pascates yang lebih tinggi dibanding nilai prates, lalu 3 (tiga) mahasiswa mengalami penurunan dan yang lainnya mendapatkan nilai yang sama untuk prates dan pascates.

Nilai rata-rata dari prates adalah 7.2 dan nilai rata-rata pascates adalah 8.9. Lalu, kami menghitung dalam bentuk persentase untuk mengetahui keterampilan menulis bahasa Perancis mahasiswa sebelum dan setelah penggunaan model pembelajaran Jigsaw. Persentase untuk nilai rata-rata prates adalah $7.2 \%$ dan untuk pascates adalah
$8.9 \%$. Kami selanjutnya menyimpulkan bahwa terdapat kenaikan antara dua persentase tersebut sampai 1.7\%. lalu, berdasarkan perhitungan statistik, nilai $t_{\text {hitung }}$ adalah 5.1 dan nilai $t_{\text {tabel }} 2.74$ yang didapat dari tabel signifikansi $1 \%$ dan derajat kebebasan 31, maka nilai $t_{\text {hitung }}>$ $t_{\text {tabel }}$ (nilai $t_{\text {hitung }}$ lebih dari $t_{\text {tabel }}$ ) dapat dikatakan bahwa hipotesis kerja $\left(\mathrm{H}_{\mathrm{k}}\right)$ diterima atau penggunaan model pembelajaran Jigsaw efektif dalam keterampilan menulis teks argumentatif dalam bahasa Perancis.

Selanjutnya, hasil perhitungan angket menunjukkan bahwa secara umum $(78 \%)$ 
mahasiswa menyukai menulis bahasa Perancis namun mereka menemukan banyak kesulitan dalam menulis. Dalam hal model pembelajaran Jigsaw, sebagian besar mahasiswa berpendapat bahwa model pembelajaran Jigsaw dapat membantu dalam menulis teks argumentatif: mendapat kemudahan karena pembelajaran dilakukan secara berkelompok; dan juga memudahkan karena terdapat sesi diskusi untuk membahas materi.

Menurut mahasiswa, kelebihan model pembelajaran Jigsaw di antaranya: 1) mahasiswa dapat dengan mudah mengembangkan teks yang dibuat karena model pembelajaran ini menyenangkan dan menarik; 2) mahasiswa dapat dengan mudah menemukan ide baru karena diskusi yang dilakukan di "kelompok ahli"; 3) mahasiswa menjadi sangat mudah mengerti materi yang diajarkan, dan; 4) model pembelajaran Jigsaw dapat meningkatkan keterampilan berkomunikasi atau mengungkapkan opini mahasiswa. Adapun kekurangan dari penerapan model pembelajaran Jigsaw dalam pembelajaran menulis teks deskriptif Bahasa Perancis Antara lain: 1) situasi kelas menjadi tidak kondusif; 2) mahasiswa menjadi kurang fokus.

\section{SIMPULAN}

Merujuk pada hasil penelitian, dapat diperoleh kesimpulan bahwa:1) Berdasarkan perhitungan nilai rata-rata prates dan pascates, dapat disimpulkan bahwa keterampilan menulis bahasa Perancis mahasiswa Departemen Pendidikan Bahasa Perancis Semester VI kelas A meningkat sesudah menggunakan model pembelajaran Jigsaw. Data hasil perhitungan menunjukkan persentase rata-rata nilai prates $7.2 \%$ dan persentase rata-rata nilai pascates $8.9 \%$, dengan kata lain, tingkat menulis teks argumentatif bahasa Perancis mahasiswa sebelum diberi perlakuan adalah $7.2 \%$, maka terdapat kenaikan rata-rata nilai pascates dibandingkan dengan rata-rata nilai prates sebesar $1.7 \%$; 2) Hasil analisis data penelitian dapat disimpulkan bahwa model pembelajaran Jigsaw efektif digunakan dalam keterampilan menulis bahasa Perancis terhadap 32 orang mahasiswa Departemen Pendidikan Bahasa Perancis Semester VI Kelas A. Hal tersebut dibuktikan dengan nilai $t_{\text {hitung }}$ sebesar 5.1 dan nilai $t_{\text {tabel }}$ 2.74, dan 3) Dari hasil pengolahan angket, dapat disimpulkan bahwa pada umumnya, mahasiswa menyukai menulis bahasa Perancis namun mereka menemukan banyak kesulitan ketika menulis bahasa Perancis dan juga mahasiswa memberikan kesan positif terkait model pembelajaran Jigsaw dalam keterampilan menulis bahasa Perancis, yaitu menambah ide dan gagasan penulisan dari hasil diskusi, dapat lebih memahami materi yang diberikan karena dipelajari lebih dalam dan sederhana dengan teman sekelompok, dan meningkatkan kemampuan berbicara atau menjadikan aktif dalam mengutarakan pendapat. Adapula kelebihan model pembelajaran Jigsaw, yaitu: (1) mahasiswa dapat mengembangkan dengan lebih tulisannya karena model pembelajaran yang menyenangkan dan menarik, (2) model pembelajaran Jigsaw membuat mahasiswa mendapat ide atau gagasan penulisan dari hasil diskusi dengan "tim ahli", (3) mahasiswa dapat lebih memahami materi yang diberikan karena dipelajari lebih dalam dan sederhana dengan teman sekelompok, (4) meningkatkan kemampuan berbicara atau menjadikan aktif dalam mengutarakan pendapat, meningkatkan kemampuan sosial dari diskusi kelompok. Sedangkan kekurangan model pembelajaran Jigsaw adalah: (1) Situasi kelas menjadi tidak kondusif; dan (2) Mahasiswa menjadi kurang fokus.

\section{DAFTAR RUJUKAN}

Anggraeni, K., \& Yonanda, D. A. (2018). Efektivitas Bahan Ajar Berbasis Kearifan Lokal Dalam Model Pembelajaran Teknik Jigsaw Terhadap Keterampilan Menulis Deskripsi. Visipena Journal, 9(2), 385395.

Artut, P.D., \& Tarim, K. (2007). The effectiveness of jigsaw II on prospective elementary school 
teachers. Asia-Pacific Journal of Teacher Education, 35(2), 129-141.

Conseil de l'Europe. (2005). Cadre européen commun de référence pour les langues: apprendre, enseigner, évaluer. Paris: Didier.

Iskandarwassid, \& Sunendar, D. (2008). Strategi Pembelajaran Bahasa. Bandung: PT. Remaja Rosda Karya.

Keraf, G. (2004). Argumentasi dan Narasi: Komposisi Lanjutan. Jakarta: PT. Gramedia Pustaka Utama.

Kurbani, S., \& Sulissiawan, A. (2015). Peningkatan Keterampilan Menulis Teks Negosiasi dengan Menggunakan Model Jigsaw pada Siswa SMA. Jurnal Pendidikan dan Pembelajaran Khatulistiwa, 4(11).

Le Monde. (n.d.) Les formes de l'argumentation. https://www.lemonde.fr/revisiondu-bac/annales-bac/francaispremiere/les-formes-de-largumentation_1-fra-09.html

Majid, A. (2013). Strategi Pembelajaran. Bandung: PT. Remaja Rosdakarya.
Mijon, P. (2010) Communication authentique et didactique en classe de FLE. [online] http://www.fle-philippemijon.com/ pratique-de-classe/communicationsauthentique-et-didactique-en-classede-FLE/

Sunendar, D., Cahyani, D., \& Mulyadi, Y. (2014). Implementasi metode ecriture créative berbasis budaya lokal untuk meningkatkan keterampilan menulis Bahasa Perancis Level B1 DELF. Jurnal Pendidikan Bahasa dan Sastra, 14(2), 230-241.

DOI: https://doi.org/10.17509/bs _jpbsp.v14i2.721

Syahrin, A. (2015). Perbandingan Hasil Belajar Keterampilan Menulis Resensi Melalui Metode Jigsaw dan Discovery Learning. Lentera: Jurnal Ilmiah Sains dan Teknologi, 15(13), 149-292.

Warsono, H., \& Hariyanto, M. S. (2012). Pembelajaran aktif teori dan asesmen. Bandung: PT Remaja Rosdakarya. 